\title{
Occupational exposure to asphalt mixture during road paving is related to increased mitochondria DNA copy number: a cross- sectional study
}

Yiyi Xu ${ }^{1 *}$ (D), Christian H. Lindh ${ }^{1}$, Bo A. G. Jönsson ${ }^{1 \wedge}$, Karin Broberg ${ }^{1,2}$ and Maria Albin ${ }^{1,3}$

\begin{abstract}
Background: Asphalt workers are exposed to polyaromatic hydrocarbons (PAHs) from hot mix asphalt via both inhalation and dermal absorption. The use of crumb rubber modified (CRM) asphalt may result in higher exposure to PAHs and more adverse effects. Our aim is to assess occupational exposure to PAHs from conventional and CRM asphalt paving by measuring PAH metabolites in urine, and to investigate the effects on mitochondrial DNA copy number (mtDNAcn) and telomere length.
\end{abstract}

Methods: We recruited 116 workers paving conventional asphalt, 51 workers paving CRM asphalt and 100 controls in Sweden, all males. A repeated-measures analysis included 31 workers paving both types of asphalt. Urine and blood samples were collected pre-working on Monday morning and post-working on Thursday afternoon after 4 days working. PAH metabolites: 1-hydroxypyrene (1-OH-PYR) and 2-hydroxyphenanthrene (2-OH-PH) were measured in urine by LC-MS/MS. Relative mtDNAcn and telomere length were measured by quantitative PCR.

Results: Conventional and CRM asphalt workers showed higher 1-OH-PYR and 2-OH-PH than controls ( $p<0.001$ for all). Relative mtDNAcn were 0.21 units $(p<0.001)$ higher in conventional asphalt workers and 0.13 units $(p=0.010)$ higher in CRM asphalt workers compared to controls. Relative telomere length did not differ across occupational groups, but it was positively associated with increment of $2-\mathrm{OH}-\mathrm{PH}(\beta=0.075, p=0.037)$ in asphalt workers. The repeated-measures analysis showed no difference in either increment of 1-OH-PYP, or changes in effect biomarkers ( $m$ tDNAcn or telomere length) between paving with conventional and CRM asphalt. Increment of 2-OH-PH was smaller after paving with CRM asphalt.

Conclusions: Road asphalt paving in open areas resulted in PAHs exposure, as shown by elevation of PAH metabolites in urine. Asphalt workers may experience oxidative stress, evidenced by alternation in mtDNAcn; however the effects could not be fully explained by exposure to PAHs from the asphalt mixture.

Keywords: Mitochondrial DNA, Telomere length, Asphalt, Occupational exposure polyaromatic hydrocarbons

\footnotetext{
* Correspondence: yiyi.xu@med.lu.se

Deceased

${ }^{1}$ Division of Occupational and Environmental Medicine, Laboratory Medicine,

Lund University, Scheelevägen 2, 22363 Lund, Sweden

Full list of author information is available at the end of the article
} 


\section{Background}

Hot asphalt emits a complex mixture of fumes, vapours and solid particulates containing hundreds of different compounds and carcinogens, such as polyaromatic hydrocarbons (PAHs), during paving application [1]. Many studies have been carried out to define the physical and chemical characteristics of asphalt fumes, as well as exposure levels and health effects in the work environment over the decades [2, 3], however, uncertainties still remained regarding exposure to asphalt fumes and related health effects due to the complexity of the asphalt fumes. Furthermore, studies have shown that skin uptake of components of the asphalt mixture is another important exposure pathway, especially for PAHs $[4,5]$. Thus, asphalt workers are occupationally exposed to PAHs via both inhalation and dermal absorption [6]. It has been reported that exposure to asphalt mixture is related to increase in airway symptoms, decrease in lung function and increase in lung cancer incidence $[3,7,8]$. However, studies also found that it is difficult to disengage the role of asphalt exposure in itself from other potential exposures such as coal tar and smoking [9]. Recently, the International Agency for Research on Cancer (IARC) classified occupational exposures to conventional asphalt and its emissions during road paving as Group 2B (possibly carcinogenic to humans) [10]. Moreover, a technique of adding recycled crumb rubber to asphalt (crumb rubber modified asphalt, CRM asphalt) has been introduced to increase long-term performance and reduce traffic noise as compared to conventional asphalt (petroleum derived) [11]. Still, CRM asphalt paving could amplify toxic emissions due to higher processing temperatures (around 177 to $220^{\circ} \mathrm{C}$ ) and emissions from the crumb rubber additives [12]. Higher exposures to PAHs and particles during CRM asphalt work compared to conventional asphalt work have been described, as well as higher rates of acute irritation of eye, nose and throat in CRM asphalt workers than in conventional asphalt workers [13]. Experimental studies also showed a higher emission of particles from CRM asphalt than from conventional asphalt (Nilsson P, Bergendorf U, Tinnerberg H, Nordin E, Gustavsson M, Strandberg B, Albin M Gudmundsson. A Emissiond into the air from hitumen and rubber hitumen-implications for asphalt workers' exposure, unpublished).

Oxidative stress is a widely accepted underlying mechanism between exposure to particles or chemicals and various adverse health outcomes. Lately, mitochondrial DNA (mtDNA) has become a biomarker of interest for oxidative stress. MtDNA lacks histones and has limited DNA repair capacity and it is therefore highly susceptible to oxidative DNA damage [14]. Reports have found that alteration of mtDNA content in peripheral blood can be related to toxic exposures, such as PAHs and benzene $[15,16]$, and mitochondria have been suggested to be a target for environmental pollutants [17]. Telomeres, as a tandem repeat sequence of TTAGGG located at the ends of the chromosomes that play a key role in chromosomal integrity, are also highly sensitive to oxidative stress $[18,19]$. Changes in telomere length (TL) in peripheral blood have been related to different toxic exposures [20, 21]. Moreover, shorter TL seems to predict chromosomal instability [22] and the risk of several chronic diseases including cancer at several sites $[23,24]$, cardiovascular disease, diabetes and chronic obstructive pulmonary disease [25-27].

In this study, we assessed the current exposure to PAHs from both conventional and CRM asphalt by measuring PAH metabolites in urine to reflect a total internal dose of PAHs from inhalation and skin uptake; and investigated potential effects of exposure by measuring mtDNA copy number (mtDNAcn) and TL in peripheral blood. We also investigated if there was any difference in exposure and effects between conventional and CRM asphalt paving.

\section{Methods \\ Study participants}

The study population included 167 asphalt workers and 100 controls in Sweden. The asphalt workers were mainly employees of 4 large road construction and maintenance companies, and the workers were exposed to asphalt mixture when paving roads and pedestrian zones outdoors. There were 116 workers laying conventional asphalt and 51 laying CRM asphalt. For the conventional asphalt workers, the inclusion criterion was no exposure to CRM asphalt for at least 3 months. The controls worked with green area maintenance and were employees of the companies or municipal departments, performing manual outdoor work but with no known occupational exposure to asphalt mixture. All participants were male. The participants were investigated twice over 4 consecutive working days: pre-exposure on Monday morning (after a 72-h exposure-free period); and post-exposure on Thursday afternoon. The investigations took place from 2012 to 2015. The asphalt workers were investigated between April and October since this is the road paving season in Sweden; while around 50\% of the controls were investigated between January and March due to availability. Among the asphalt workers laying CRM asphalt, 31 workers were also laying conventional asphalt occasionally. These workers were investigated twice (pre- and post-working) when laying CRM asphalt, and twice (preand post-working) when laying conventional asphalt at different period, therefore, a repeated-measures analysis was performed based on these 31 workers to compare conventional and CRM asphalt for biomarkers of exposure and toxicity. 
All study participants gave informed written consent to take part in the study and the study was approved by the Regional Ethical Review Board in Lund, Sweden.

\section{Questionnaire investigation}

One structured questionnaire was sent out to the participants one week before the field investigation. The questionnaire contained questions about working history (including potential particle exposure), medical history, smoking and smokeless tobacco "snus" (a moist snuff placed under the upper lip) history, medication, daily diet (fish, vegetable and fruit consumption), physical activity and recent respiratory symptoms. The questionnaire was handed in pre-working on Monday morning and was checked for omissions and inconsistencies during the examination by the occupational health nurse.

\section{Blood and urine sampling}

First morning urine samples were collected pre-exposure on Monday morning, while spot urine samples were collected post-exposure on Thursday afternoon. All urine samples were transported to the laboratory at room temperature and stored at $-20{ }^{\circ} \mathrm{C}$ for further analysis.

Peripheral blood samples were obtained pre- and postexposure onsite and transported to the laboratory on dry ice and stored at $-20{ }^{\circ} \mathrm{C}$ until extraction of DNA.

\section{Analysis of PAH metabolites in urine}

We measured four PAH metabolites: 1-hydroxypyrene (1-OH-PYR), 2-hydroxyphenanthrene (2-OH-PH), 3hydroxybenzo[a]pyrene (3-OH-BaP) and 3-hydroxy ben$\mathrm{z}$ [a]anthracene (3-OH-BaA) from both pre- and postworking urine samples. 1-OH-PYR is a metabolite of pyrene and has been extensively used as a proxy for total exposure to $\mathrm{PAH}[28]$. 2-OH-PH was chosen as the metabolite of phenanthrene, since asphalt fumes contains high concentration of phenanthrene [29]. It has been suggested that 2-OH-PH can be the most promising candidate of biomarkers of exposure to asphalt emissions [5]. 3-OH-BaP as metabolite of benzo[a]pyrene and $3-\mathrm{OH}-\mathrm{BaA}$ as metabolite of benz[a]anthracene were chosen since they can be found in asphalt fumes emission [29] and benzo(a)pyrene is classified as carcinogenic to human (IARC group 1) [30]. For the quantitative analysis, liquid chromatography coupled to tandem mass spectrometry was used (LC-MS/MS; QTRAP 5500, AB Sciex, Foster City, CA, USA). The urine samples were hydrolysed using glucuronidase and internal standards for all compounds were added. For analysis of $1-\mathrm{OH}-$ PYR and 2-OH-PH, sample aliquots were injected into a single C18 column according to Svendsen et al. [31]. A two dimensional LC system was used for analysis of 3$\mathrm{OH}-\mathrm{BaP}$ and 3-OH-BaA. All samples were prepared in duplicates and the average concentrations were used.
The analyses of 1-OH-PYR were part of a round robin inter-laboratory programme (University of ErlangenNuremberg, Germany) with results within the tolerance limits. Creatinine in urine was analysed using an enzymatic method and used for adjustment of urinary dilution (as $\mu \mathrm{mol}$ per mol creatinine) [32]. The limits of detection (LODs) were estimated from the blank samples and were $0.2 \mathrm{nmol} / \mathrm{L}$ for $1-\mathrm{OH}-\mathrm{PYR}$ and $2-\mathrm{OH}-\mathrm{PH}$, and 0 . $05 \mathrm{nmol} / \mathrm{L}$ for $3-\mathrm{OH}-\mathrm{BaP}$ and $3-\mathrm{OH}-\mathrm{BaA}$. Samples below LODs still have measured values, but with lower certainty. There were 79 (15\%) samples below LOD for 1-OH-PYP and two (0.4\%) samples below LOD for 2-OH-PH. The measured concentrations of the samples below LODs for 1-OH-PYP and 2-OH-PH were still used in statistical analysis. The concentrations of 3-OH$\mathrm{BaP}$ and $3-\mathrm{OH}-\mathrm{BaA}$ were not evaluated since more than $95 \%$ of the samples were below the LODs. For more details on the method see Additional file 1.

\section{Analysis of relative quantitation of mitochondrial DNA copy number and telomere length in blood}

Post-exposure peripheral blood samples were used to extract DNA for all participants. DNA was additionally extracted from pre-exposure samples from the 31 workers involved in the repeated-measures analysis. All DNA extractions were performed by using Qiagen DNA Blood Midi kit (Qiagen, Heidelberg, Germany).

As described previously, SYBR Green-based realtime quantitative PCR (7900HT, Applied Biosystems, Foster City, CA, USA) was used to determine relative mtDNAcn and TL [32]. Master mixes for mtDNA and hemoglobin beta $(H B B)$ gene runs were prepared with KAPA SYBR FAST qPCR Kit Master Mix (2X) ABI Prism (Kapa Biosystems, Woburn, MA, USA) and corresponding primers $(0.20 \mu \mathrm{M}$ for each primer $)$ $[33,34]$. Master mixes for telomere runs were prepared with telomere primers $(0.45 \mu \mathrm{M}$ for each primer) [35], $1 \times$ PCR Buffer (Thermo Fisher Scientific, Carlsbad, CA, USA), $1.75 \mathrm{mM} \mathrm{MgCl}_{2}, 0.8 \mathrm{mM}$ dNTPs, $0.3 \mathrm{mM}$ SybrGreen (Thermo Fisher Scientific) , $1 \times$ Rox (Thermo Fisher Scientific), and 0.5 U Taq Platina (Thermo Fisher Scientific). The corresponding primers for mtDNA, telomere and $H B B$ list in Additional file 2: Table S1. One reference DNA sample was diluted serially by twofold per dilution to produce 5 concentrations of 1 $16 \mathrm{ng} / \mu \mathrm{L}$ for the standard curve. The standard curve, samples and one blank (sample with no template) were run in triplicates with $2.5 \mu \mathrm{l}$ DNA $(4 \mathrm{ng} / \mu \mathrm{L})$ in each reaction. Each run was completed by melting curve analysis, and agarose gel electrophoresis of PCR products was performed for randomly picked samples to confirm the amplification specificity and absence of primer dimers.

$\mathrm{R}^{2}$ for each standard curve was $>0.99$. Standard deviations of triplicates $<0.1$ were accepted for the $C_{t}$ 
values. SDS 2.4.1 software (Thermo Fisher Scientific) calculated the average relative quantity of triplicate measurements of mtDNAcn, TL and $H B B$ for each sample based on the standard curve. Then, the average relative quantity of mtDNAcn was divided by the average quantity of $H B B$ to calculate the mtDNA/ $H B B$ ratio (relative mtDNAcn). Likewise, the relative TL was the quotient of the average quantity of $\mathrm{TL}$ and $H B B$. Both relative mtDNAcn and TL are therefore arbitrary values. The CVs based on 4 runs were $9.1 \%$ for mtDNAcn and $7.5 \%$ for TL.

\section{Statistical analysis}

Concentrations of PAH metabolites (1-OH-PYP and 2-OH-PH) were converted with natural logarithm to approach symmetric distribution and then included in model calculations. Relative mtDNAcn and TL were not converted since raw data showed close to symmetric distribution. Linear mixed model was used to compare urinary PAH metabolites across three occupational groups (conventional asphalt workers/CRM asphalt workers vs. controls) by adjusting for potential confounders (described below). General linear regression was used to analyze associations between exposure indexes [i.e. occupational groups as categorical variables, changes in urinary $\mathrm{PAH}$ metabolites (from pre- to post-working) as continuous variables] and post-working relative mtDNAcn or TL. Age (as continuous variable) was always included in the regression models. Other potential confounders [BMI (continuous variable), smoking and "snus" status (categorical variable), cigarette pack-year (continuous variable), investigation season (categorical variable), daily diet and physical activity (categorical variable)] were chosen based on published studies and general knowledge, and tested one by one in the models. Only the confounders which changed $\beta$-estimates of exposure indexes by more than $10 \%$ remained. Therefore, daily diet and physical activity were excluded.

In the repeated-measures analysis with 31 asphalt workers, absolute changes $(\Delta)$ from pre- to post-working of 1-OH-PYR, 2-OH-PH, relative mtDNAcn and TL were calculated for each subject for both conventional and CRM asphalt paving. Linear mixed models were adopted to analyze the differences in $\Delta$ values (i.e. $\triangle \mathrm{PAH}$ metabolites, $\triangle \mathrm{mtDNAcn}$ and $\Delta \mathrm{TL}$ ) between conventional and CRM asphalt paving; as well as the associations between $\triangle \mathrm{PAH}$ metabolites and $\Delta \mathrm{mtDNAcn} / \Delta \mathrm{TL}$. Pre-working levels were included in the models for adjustment.

The residuals from each linear regression model were examined and all showed symmetric distribution. All statistical analyses were completed by using SPSS 23.0 (IBM SPSS Statistics for Windows, NY, USA).

\section{Results}

Basic characteristics of study participants are presented in Table 1. Age and BMI were similar across three occupational groups. The years of asphalt work did not differ between the conventional and the CRM asphalt groups. Smoking and snus status were slightly different: there were more current smokers in CRM asphalt workers (19\%) compared to controls (12\%); and more current snus users in asphalt workers (39\%) compared to controls (21\%); however smoking or snus were not correlated with either mtDNAcn or TL (data not show). The distributions of investigation season were similar between conventional asphalt and CRM asphalt workers $(p=0.56)$, but different to controls $(p<0.001)$ since 53\% of controls were investigated during winter due to practical reason. Pre-working PAH metabolites were similar across three occupational groups, while post-working levels were different. Post-working relative mtDNAcn, but not relative TL were different across groups. Relative TL was inversely correlated with age (Fig. 1a), but relative mtDNAcn was not (Fig. 1b). TL and mtDNAcn were positively correlated (Fig. 1c). The distributions of daily diet and physical activity were similar across occupational groups, and neither of them was correlated with PAH metabolites or TL. Only daily diet was slightly correlated with mtDNAcn (Additional file 3: Table S2).

$\mathrm{Ln}(1-\mathrm{OH}-\mathrm{PYP})$ and $\ln (2-\mathrm{OH}-\mathrm{PH})$ (both pre- and postworking concentrations) showed a seasonal pattern in the conventional asphalt workers, indicating a trend of decreasing PAH exposure from spring to early autumn $(p<0.05$ for all). No such pattern was shown in either CRM asphalt workers or controls. No seasonal pattern of $\triangle \mathrm{PAH}$ metabolites during the working week was found, either (Additional file 4: Table S3). After adjusting for age, BMI, smoking and snus status and investigation season, both conventional and CRM asphalt workers showed higher $\ln (1-\mathrm{OH}-\mathrm{PYR})$ and $\ln (2-\mathrm{OH}-\mathrm{PH})$ than the controls (Table 2). The repeated-measures analysis showed that the increment of $\ln (2-\mathrm{OH}-\mathrm{PH})$ was 0 . $50 \mu \mathrm{mol} / \mathrm{mol}$ creatinine smaller after paving with CRM asphalt compared to paving with conventional asphalt (95\%CI: $-0.85--0.15)$ after adjusting for pre-working concentration. No such difference between conventional and CRM asphalt paving was found for 1-OH-PYR increment (Table 3).

Relative mtDNAcn, but not TL, was different between asphalt workers and controls (Table 4): mtDNAcn was 0 . 21 units (95\%CI: 0.13-0.29) higher in conventional asphalt workers and 0.13 units (95\%CI: 0.033-0.24) higher in CRM asphalt workers compared to controls. The analysis of dose-response associations between short-term exposure to PAH and relative mtDNAcn or TL among all asphalt workers showed that changes in PAH metabolites were positively associated with TL, but 
Table 1 Basic characteristics, PAH metabolites, mtDNAcn and TL for conventional asphalt workers, crumb rubber modified (CRM) asphalt workers and controls ${ }^{a}$

\begin{tabular}{|c|c|c|c|c|c|}
\hline & $\begin{array}{l}\text { Conventional asphalt workers } \\
(n=116)\end{array}$ & $\begin{array}{l}\text { CRM asphalt workers } \\
(n=51)\end{array}$ & $\begin{array}{l}\text { All asphalt workers } \\
(n=167)\end{array}$ & $\begin{array}{l}\text { Controls } \\
(n=100)\end{array}$ & $p^{b}$ \\
\hline Age & $43(24-59)$ & $42(22-61)$ & $43(23-59)$ & $46(24-62)$ & 0.29 \\
\hline $\mathrm{BMI}\left(\mathrm{kg} / \mathrm{m}^{2}\right)$ & $28(22-38)$ & $28(23-35)$ & $28(23-38)$ & $27(22-36)$ & 0.89 \\
\hline Length of asphalt working (year) & $12(1-30)$ & $10(1-38)$ & $12(1-35)$ & - & - \\
\hline Smoking & & & & & 0.066 \\
\hline Never smoker & $84(74 \%)$ & $31(70 \%)$ & $115(73 \%)$ & $65(65 \%)$ & \\
\hline Previous smoker & $24(21 \%)$ & $5(11 \%)$ & $29(18 \%)$ & $23(23 \%)$ & \\
\hline Current smoker & $6(5 \%)$ & $8(19 \%)$ & $14(9 \%)$ & $12(12 \%)$ & \\
\hline Cigarette pack-year if ever smoked & $9(2-30)$ & $18(1-95)$ & $10(1-38)$ & $14(1-54)$ & 0.083 \\
\hline Snus & & & & & 0.014 \\
\hline Never snus user & $54(47 \%)$ & $25(57 \%)$ & 79 (50\%) & $66(66 \%)$ & \\
\hline Previous snus user & $15(13 \%)$ & $2(5 \%)$ & $17(11 \%)$ & $13(13 \%)$ & \\
\hline Current snus user & $45(40 \%)$ & $17(38 \%)$ & $62(39 \%)$ & $21(21 \%)$ & \\
\hline Investigation Season & & & & & $<0.001$ \\
\hline Spring (Apr-Jun) & $44(38 \%)$ & $17(40 \%)$ & $61(39 \%)$ & $26(26 \%)$ & \\
\hline Summer (Jul-Aug) & $38(33 \%)$ & $10(24 \%)$ & $48(30 \%)$ & $18(18 \%)$ & \\
\hline Early autumn (Sep-Oct) & $34(29 \%)$ & $15(36 \%)$ & 49 (31\%) & $3(3 \%)$ & \\
\hline Winter (Jan-Mar) & $0(0 \%)$ & $0(0 \%)$ & $0(0 \%)$ & $53(53 \%)$ & \\
\hline Pre- working 1-OH-PYR ( $\mu \mathrm{mol} / \mathrm{mol}$ creatinine) & $0.041(0.018-0.11)$ & $0.042(0.011-0.17)$ & $0.041(0.017-0.13)$ & $0.028(0.0087-0.091)$ & 0.12 \\
\hline Post- working 1-OH-PYR ( $\mu \mathrm{mol} / \mathrm{mol}$ creatinine) & $0.068(0.024-0.24)$ & $0.11(0.020-0.76)$ & $0.076(0.021-0.27)$ & $0.028(0.0092-0.091)$ & $<0.001$ \\
\hline Pre- working 2-OH-PH ( $\mu \mathrm{mol} / \mathrm{mol}$ creatinine) & $0.13(0.063-0.55)$ & $0.14(0.061-0.51)$ & $0.13(0.063-0.52)$ & $0.095(0.040-0.65)$ & 0.18 \\
\hline Post- working 2-OH-PH ( $\mu \mathrm{mol} / \mathrm{mol}$ creatinine) & $0.20(0.071-0.62)$ & $0.24(0.077-0.90)$ & $0.21(0.076-0.69)$ & $0.082(0.039-0.47)$ & $<0.001$ \\
\hline Post-working relative mtDNAcn & $0.98(0.70-1.6)$ & $0.97(0.72-1.3)$ & $0.98(0.70-1.5)$ & $0.87(0.56-1.3)$ & $<0.001$ \\
\hline Post-working relative TL & $1.1(0.76-1.6)$ & $1.2(0.73-1.8)$ & $1.1(0.73-1.7)$ & $1.1(0.72-1.7)$ & 0.29 \\
\hline
\end{tabular}

${ }^{a}$ Values are median (5-95 percentile) for continuous variables, or $\mathrm{n}(\%)$ for categorical variables

${ }^{\mathrm{b}} \mathrm{P}$ values for age, BMI, cigarette pack-year, 1-OH-PYR, 2-OH-PH, relative mtDNA copy number and relative telomere length were derived from one-way ANOVA and $P$ values for smoking, snus status and investigation season were derived from Fisher's exact test to test the differences across three occupational groups

none of them was associated with mtDNAcn (Table 5). In the repeated-measures analysis, no difference was found in either change in relative mtDNAcn or change in TL from pre- to post-working among the same workers paving with conventional and CRM asphalt (Additional file 5: Table S4). However, a negative association was found between change in 1-OH-PYP and change in mtDNAcn during the working week among 31 workers in the repeated-measures analysis (Table 5), indicating that a short-term higher exposure to pyrene from asphalt mixture was associated with less increment of mtDNAcn ( $\beta=-0.078$, 95\%CI: $-0.14--0.016)$.

\section{Discussion}

Road paving asphalt workers, both paving with conventional and CRM asphalt are exposed to PAHs, evidenced by higher 1-OH-PYR and 2-OH-PH in the workers. However, the exposure levels were not as high as in other studies of asphalt workers [36, 37]. Asphalt workers seem to experience moderate oxidative stress from this occupation, as indicated by higher relative mtDNAcn than controls; however, such alternation could not be fully explained by PAHs from asphalt mixture.

In this study, we measured urinary PAH metabolites to reflect the total internal dose of PAHs from inhalation and dermal exposure, and our observations of clear increases in the PAH metabolites among the exposed workers but not among the controls are in accordance with other studies of asphalt paving workers $[28,38]$. However, it should be noted that 1-OH-PYR concentrations in the present study were much lower than reported in the other studies on asphalt workers performed in different countries in Europe [36, 37]. The relatively low PAHs exposure can also be seen in the air measurements in our study (median concentrations for total airborne PAHs were around 2.8 and $2.6 \mu \mathrm{g} / \mathrm{m}^{3}$ for conventional and CRM asphalt, respectively) (Xu Y, Kåredal M, Nielsen J, Adlercreutz M, Bergendorf U, Strandberg B, Antonsson AB, Tinnerberg $\mathrm{H}$, Albin $\mathrm{M}$ : Exposure, respiratory symptoms, lung 

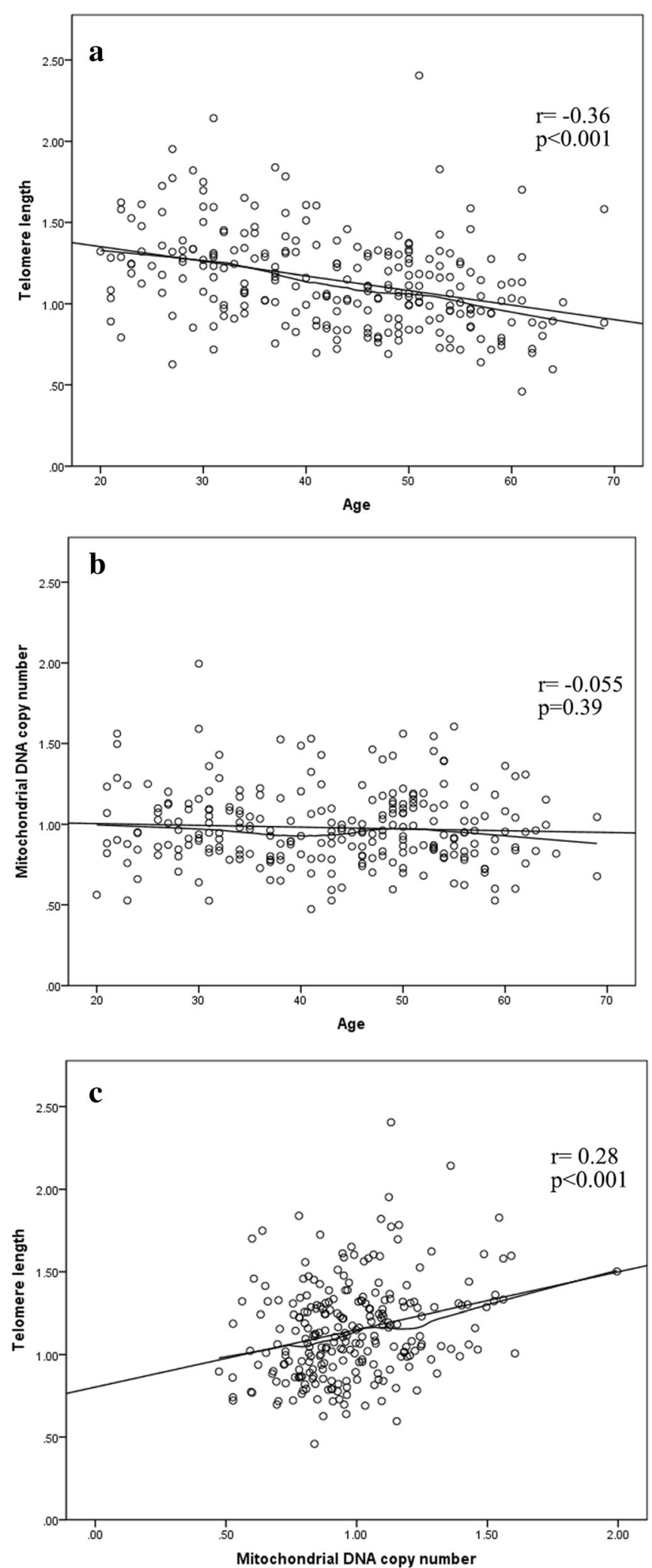

Fig. 1 Correlations between telomere length, mitochondrial DNA copy number and age. Scatterplots with linear and loess fit lines showing that telomere length was inversely correlated with age (a), and positively correlated with mitochondrial DNA copy number (c). Mitochondrial DNA copy number was not correlated with age (b) 
Table 2 Differences of urinary 1-OH-PYR and 2-OH-PH in three occupational groups ${ }^{\mathrm{a}}$

\begin{tabular}{|c|c|c|c|c|}
\hline PAH metabolites & Occupational groups & Adjusted mean (95\%Cl) & $\beta(95 \% \mathrm{Cl})$ & $p$ \\
\hline \multirow[t]{3}{*}{$\ln (1-\mathrm{OH}-\mathrm{PYR})$} & Conventional asphalt workers & $-2.6(-2.8,-2.4)$ & $0.76(0.54,0.97)$ & $<0.001$ \\
\hline & CRM asphalt workers & $-2.5(-2.8,-2.3)$ & $0.85(0.58,1.1)$ & $<0.001$ \\
\hline & Control & $-3.4(-3.6,-3.2)$ & 0 & - \\
\hline \multirow[t]{3}{*}{$\ln (2-\mathrm{OH}-\mathrm{PH})$} & Conventional asphalt workers & $-1.6(-1.8,-1.5)$ & $0.58(0.36,0.79)$ & $<0.001$ \\
\hline & CRM asphalt workers & $-1.6(-1.9,-1.4)$ & $0.58(0.31,0.85)$ & $<0.001$ \\
\hline & Control & $-2.2(-2.4,-2.0)$ & 0 & - \\
\hline
\end{tabular}

${ }^{a}$ Adjusted mean, $\beta$ estimates and $p$ values were derived from linear mixed model after adjusting for age, BMl, smoking and snus status, cigarette pack-year and investigation season. The controls are the reference group

function and inflammation response of road paving asphalt workers. Submitted), which were lower than the current threshold limit value (TLV: $200 \mu \mathrm{g} / \mathrm{m}^{3}$ ) set by the American Conference of Governmental Industrial Hygienists (ACGIH) [39]. A smaller increment of 2-OH$\mathrm{PH}$ after CRM asphalt paving was noted among 31 workers in the repeated-measures analysis, indicating that the workers were exposed to less phenanthrene when paving with CRM asphalt than with conventional asphalt. Such finding is different from U.S. studies reporting higher PAH emissions from CRM paving $[13,40]$ and our laboratory measurements of our project (Nilsson P, Bergendorf U, Tinnerberg H, Nordin E, Gustavsson M, Strandberg B, Albin M, Gudmundsson A. Emissions into the air from bitumen and rubber bitumen-implications for asphalt workers' exposure. Unpublished). The contradictory findings may due to the modest sample size in our study. Besides, paving temperature could be a more important determinate factor of PAH emissions. It has been shown that paving at higher temperatures is associated with higher exposure levels [3, 41].

Given the fact that mtDNA and telomeres are highly sensitive to damage by oxidative stress, together with the evidence that both mtDNAcn and TL may be influenced by short-term particle exposure [42, 43], we hypothesized that these two biomarkers are dynamic and can be affected by short-term exposure to PAHs. Higher relative mtDNAcn in asphalt workers may indicate moderate oxidative stress in this occupation. The asphalt workers may hypothetically experience a compensatory response: mtDNA synthesis is stimulated to produce more energy for damaged mitochondria disposal and cell survival under low to moderate oxidative stress [44]. Earlier studies on exposure to PAHs and response of mtDNA have shown conflicting results. Pavanello $\mathrm{S}$ et al. found a positive association between urinary 1-OH-PYP and mtDNAcn among cokeoven workers [15]. Kim HY et al. reported increased mtDNAcn in human leukaemiaderived cell lines and bone marrow-derived mesenchymal stem cells after PAHs treatment at a concentration of $100 \mu \mathrm{M}$ [45]. However, Pieters $\mathrm{N}$ et al. showed decreased mtDNAcn in association with indoor exposure to PAHs during wintertime [46]. One reason for these conflicting results could be that different exposure levels and exposure length can result in different responses in the body. The dose-response of short-term $\mathrm{PAH}$ exposure on mtDNAcn was uncertain. We did not find associations between changes in $\mathrm{PAH}$ metabolites and post-working mtDNAcn among all asphalt workers. However, we found a higher increment of 1-OH-PYP in association with less increment in mtDNAcn during four days among 31 workers in the repeated-measures analysis. One explanation could be that other compounds than PAHs in the asphalt mixture, e.g. nitrosamines, or unmeasured co-exposures, e.g. traffic pollutions, were truly responsible for the increased mtDNAcn, while the short-term effect (repeated-measures analysis) of PAH could, as an acute response, be associated with decreased mtDNAcn.

The dose-response effect of short-term PAHs exposure on relative TL showed positive associations between changes in 1-OH-PYR and 2-OH-PH and post-working TL, but no association with change in TL during four days in the repeated-measures analysis. One may infer

Table 3 Differences of changes $(\Delta)$ in urinary 1-OH-PYR and 2-OH-PH between conventional and CRM asphalt paving in the repeated-measures analysis $(N=31)^{a}$

\begin{tabular}{lllll}
\hline$\Delta$ PAH metabolites & Type of asphalt paving & Adjusted mean $(95 \% \mathrm{Cl})$ & $\beta(95 \% \mathrm{Cl})$ & $\mathrm{P}$ \\
\hline$\Delta \ln (1-\mathrm{OH}-\mathrm{PYR})$ & Conventional asphalt paving & $0.86(0.56,1.2)$ & 0 & - \\
& CRM asphalt paving & $0.86(0.57,1.2)$ & $0.0068(-0.37,0.38)$ & 0.97 \\
$\Delta \ln (2-\mathrm{OH}-\mathrm{PH})$ & Conventional asphalt paving & $0.88(0.62,1.1)$ & 0 & - \\
& CRM asphalt paving & $0.38(0.13,0.62)$ & $-0.50(-0.85,-0.15)$
\end{tabular}

${ }^{a}$ Adjusted mean, $\beta$ estimates and $p$ values were derived from linear mixed model after adjusting for pre-working PAH metabolites levels. Conventional asphalt paving are the reference group 
Table 4 Differences of post-working relative mtDNAcn and TL in three occupational groups

\begin{tabular}{|c|c|c|c|c|c|c|c|c|}
\hline \multirow[b]{3}{*}{ Occupational groups } & \multicolumn{4}{|c|}{ Post-working mtDNAcn } & \multicolumn{4}{|l|}{ Post-working TL } \\
\hline & \multicolumn{2}{|l|}{ Partly adjusted $^{a}$} & \multicolumn{2}{|l|}{ Fully adjusted $^{\mathrm{b}}$} & \multicolumn{2}{|l|}{ Partly adjusted ${ }^{a}$} & \multicolumn{2}{|l|}{ Fully adjusted $^{\mathrm{b}}$} \\
\hline & $\beta(95 \% \mathrm{Cl})$ & $p$ & $\beta(95 \% \mathrm{Cl})$ & $p$ & $\beta(95 \% \mathrm{Cl})$ & $p$ & $\beta(95 \% \mathrm{Cl})$ & $\mathrm{p}$ \\
\hline Conventional asphalt & $0.14(0.076,0.20)$ & $<0.001$ & $0.21(0.13,0.29)$ & $<0.001$ & $-0.029(-0.10,0.046)$ & 0.45 & $-0.017(-0.12,0.085)$ & 0.74 \\
\hline CRM asphalt & $0.084(0.0018,0.17)$ & 0.045 & $0.13(0.033,0.24)$ & 0.010 & $0.045(-0.054,0.14)$ & 0.37 & $0.064(-0.065,0.19)$ & 0.33 \\
\hline Controls & 0 & - & 0 & - & 0 & - & 0 & - \\
\hline All asphalt workers & $0.12(0.065,0.18)$ & $<0.001$ & $0.20(0.12,0.28)$ & $<0.001$ & $-0.0084(-0.079,0.062)$ & 0.82 & $0.0011(-0.098,0.10)$ & 0.98 \\
\hline Controls & 0 & - & 0 & - & 0 & - & 0 & - \\
\hline
\end{tabular}

a Partly adjusted linear regression model: only adjusted for age

${ }^{b}$ Fully adjusted linear regression model: adjusted for age, BMl, smoking and snus status, cigarette pack-year and investigation season

that the short-term PAHs exposure has no effect on TL within four days, or our study was not powerful enough to detect the difference. Yet we could not rule out the possibility that it may affect TL as a long-term effect. Studies of coke-oven workers in Chinese and European populations reported short TL in related to PAHs exposure $[20,47]$. The exposure levels in those studies were much higher (median urinary 1-OH-PYR: $12.2 \mu \mathrm{mol} /$ mol creatinine in Chinese study and 3.09 in European study) than in our study (0.08 for all asphalt workers), indicating the possible TL shortening effect of PAHs exposure may only happen at higher exposure level. Instead, short-term exposure to low level of PAHs in asphalt workers may induce acute inflammatory response [48], which can cause influx of "younger" inflammatory cells with longer TL to the blood or activation of telomerase to elongate TL [49], which may take place during weeks.

There were some limitations with our study. The number of workers involved in paving with CRM asphalt was small and may have limited our possibilities to discern differences in exposure and effects as compared to conventional asphalt paving. Asphalt paving has complex exposure scenarios including other established carcinogens (e.g. nitrosamines) and small combustion particles. Although we performed air sampling of about 50 paving workers to monitor air-borne nitrosamines and respirable dust (Xu Y, Kåredal M, Nielsen J, Adlercreutz M, Bergendorf U, Strandberg B, Antonsson AB, Tinnerberg H, Albin $\mathrm{M}$ : Exposure, respiratory symptoms, lung function and inflammation response of road paving asphalt workers. Submitted), we could not estimate exposure levels for these co-exposures for all workers due to outdoor work complexity and large variations of asphalt mix and paving temperature, and therefore we were not able to address any associations between exposures other than PAHs and mtDNAcn or TL. The investigation season was different from asphalt workers and controls due to practical reason. As sensitivity analysis, we excluded study participants investigated in winter to improve the consistency of investigation season. The effect estimates and $p$ values were similar as the original analysis (Additional file 6: Table S5), which lends credibility to our results. On the other hand, the present study had several strengths. We prolonged the exposure period to more than a single day's working-shift. The purpose was to include the exposure and effect from the working week rather than only a single working day, and this could supposedly reduce the day-to-day variation.

\section{Conclusions}

Our results are in agreement with previous studies showing that asphalt workers are still exposed to PAHs. However,

Table 5 Associations between changes $(\Delta)$ in PAH metabolites and post-working relative mtDNAcn / TL among asphalt workers; and $\triangle \mathrm{mtDNACn} / \triangle \mathrm{TL}$ in the repeated-measures analysis

\begin{tabular}{|c|c|c|c|c|c|}
\hline \multirow[t]{2}{*}{ Study population } & \multirow{2}{*}{$\begin{array}{l}\triangle \mathrm{PAH} \\
\text { metabolites }\end{array}$} & \multicolumn{2}{|c|}{ Post-working relative mtDNAcn } & \multicolumn{2}{|l|}{ Post-working relative $\mathrm{TL}$} \\
\hline & & $\beta(95 \% \mathrm{Cl})$ & $p^{a}$ & $\beta(95 \% \mathrm{Cl})$ & $p^{a}$ \\
\hline All asphalt workers & $\Delta \ln (1-\mathrm{OH}-\mathrm{PYR})$ & $0.035(-0.028,0.098)$ & 0.28 & $0.067(-0.0038,0.14)$ & 0.064 \\
\hline \multirow[t]{3}{*}{$(N=138)$} & $\Delta \ln (2-\mathrm{OH}-\mathrm{PH})$ & $0.048(-0.015,0.11)$ & 0.14 & $0.075(0.0046,0.15)$ & 0.037 \\
\hline & & $\Delta m t D N A c n$ & & $\Delta \mathrm{TL}$ & \\
\hline & & $\beta(95 \% \mathrm{Cl})$ & $p^{b}$ & $\beta(95 \% \mathrm{Cl})$ & $p^{b}$ \\
\hline Repeated-measures analysis & $\Delta \ln (1-\mathrm{OH}-\mathrm{PYR})$ & $-0.078(-0.14,-0.016)$ & 0.015 & $-0.064(-0.16,0.028)$ & 0.17 \\
\hline$(N=31)$ & $\Delta \ln (2-\mathrm{OH}-\mathrm{PH})$ & $-0.057(-0.12,0.0073)$ & 0.080 & $-0.048(-0.15,0.049)$ & 0.32 \\
\hline
\end{tabular}

${ }^{\mathrm{a}} P$ values were derived from general linear model with age, BMI, smoking and snus states, cigarette pack-year, investigation season, and occupational groups as adjustments

${ }^{\mathrm{b}} P$ values were derived from linear mixed model with occupational groups and pre-working mtDNAcn or TL as adjustments 
the exposure levels were lower than in previous studies. Still, it seems that exposure to asphalt mixture can induce oxidative stress, as evidenced by higher relative mtDNAcn in the asphalt workers; however the associations found for mtDNAcn cannot be fully explained by exposure to PAHs from asphalt mixture. Other unavailable co-exposures during asphalt paving may have effects apart from that of PAHs, and would weaken our possibilities to observe associations. We did not find any evidence of higher PAHs exposure or more effects on mtDNAcn and TL when working with CRM asphalt compared to conventional asphalt. Paving temperature could be a more important factor than crumb rubber additives with respect of exposure and related effects.

\section{Additional files}

Additional file 1: Measurement of 1-OH-PYR, 2-OH-PH, 3-OH-BaA and 3-OH-BaP in urine (DOCX $21 \mathrm{~kb})$

Additional file 2: Table S1. Real Time PCR primers for mtDNA, telomere and hemoglobin beta (HBB) (DOCX $17 \mathrm{~kb}$ )

Additional file 3: Table S2. Distribution of daily diet and physical activity across occupational groups and their correlations with urinary PAH metabolites, mtDNAcn and TL (DOCX $21 \mathrm{~kb}$ )

Additional file 4: Table S3. Pre-, post-working and changes $(\Delta)$ in PAH metabolites in three occupational groups investigated in different investigation season. (DOCX $24 \mathrm{~kb}$ )

Additional file 5: Table S4. Differences of changes $(\Delta)$ in relative $T L$ and mtDNAcn between conventional and CRM asphalt paving in the repeated-measures analysis $(N=31)(D O C X 21 \mathrm{~kb})$

Additional file 6: Table S5. Sensitivity analysis of PAH exposures and biomarkers in three groups, excluding participants from winter. (DOCX $22 \mathrm{~kb}$ )

\section{Abbreviations}

1-OH-PYR: 1-hydroxypyrene; 2-OH-PH: 2-hydroxyphenanthrene; 3-OH-BaA: 3hydroxybenz[a]anthracene; 3-OH-BaP: 3-hydroxy benso[a]pyrene; CRM: Crumb rubber modified; HBB: Hemoglobin beta; LODs: Limits of detection; mtDNA: mitochondrial DNA; mtDNAcn: mitochondrial DNA copy number; PAHs: Polyaromatic hydrocarbons; PCR: Polymerase chain reaction; TL: Telomere length

\section{Acknowledgements}

We acknowledge the skilled assistance of Eva Assarsson, Pia Tallving and Patrice Milton for carrying out the recruitment for the study. We would also like to express our gratitude to the workers who participated in the investigation.

\section{Funding}

The study was funded by AFA Insurance and FORTE: Swedish Research Council for Health, Working Life and Welfare.

\section{Availability of data and materials}

The dataset generated and/or analyzed during the current study are not publicly available since it contains sensitive health-related data, but it is available from the corresponding author on reasonable request.

\section{Authors' contributions}

$\mathrm{MA}$ and $\mathrm{KB}$ designed the project with contribution of $\mathrm{YX}$. CL and BJ measured and provided urinary exposure biomarkers characteristics. YX measured mitochondrial DNA copy number and telomere length, analyzed the data and interpreted the results. The manuscript was written by $Y X$ and critically revised by KB and MA. All authors read, corrected and approved the manuscript.

\section{Ethics approval and consent to participate}

All study participants gave informed written consent to take part in the study. The study was approved by the Regional Ethical Review Board in Lund, Sweden.

\section{Consent for publication}

Not applicable.

\section{Competing interests}

The authors declare that they have no competing interests.

\section{Publisher's Note}

Springer Nature remains neutral with regard to jurisdictional claims in published maps and institutional affiliations.

\section{Author details}

'Division of Occupational and Environmental Medicine, Laboratory Medicine, Lund University, Scheelevägen 2, 22363 Lund, Sweden. ${ }^{2}$ Unit of Metals \& Health, Institute of Environmental Medicine, Karolinska Institutet, Stockholm, Sweden. ${ }^{3}$ Unit of Occupational Medicine, Institute of Environmental Medicine, Karolinska Institutet, Stockholm, Sweden.

Received: 5 September 2017 Accepted: 20 March 2018

Published online: 27 March 2018

\section{References}

1. Lauby-Secretan B, Baan R, Grosse Y, Ghissassi FE, Bouvard V, BenbrahimTallaa L, Guha N, Galichet L, Straif K. Bitumens and bitumen emissions, and some heterocyclic polycyclic aromatic hydrocarbons. Lancet Oncol. 2011; 12(13):1190-1.

2. Herrick RF, McClean MD, Meeker JD, Zwack L, Hanley K. Physical and chemical characterization of asphalt (bitumen) paving exposures. J Occup Environ Hyg. 2007;4(S1):209-16.

3. NIOSH National Institute for Occupational Safety and Health: Health effects of occupational exposure to asphalt. https://www.cdc.gov/niosh/docs/2001110/pdfs/2001-110.pdf. (2000). Accessed 20 Dec 2016.

4. McClean MD, Rinehart RD, Ngo L, Eisen EA, Kelsey KT, Herrick RF. Inhalation and dermal exposure among asphalt paving workers. Ann Occup Hyg. 2004;48(8):663-71.

5. Sobus JR, McClean MD, Herrick RF, Waidyanatha S, Nylander-French LA, Kupper LL, Rappaport SM. Comparing urinary biomarkers of airborne and dermal exposure to polycyclic aromatic compounds in asphalt-exposed workers. Ann Occup Hyg. 2009;53(6):561-71. https://doi.org/10.1093/ annhyg/mep042.

6. Boffetta $P$, Burstyn I, Partanen $T$, Kromhout $H$, Svane $\mathrm{O}$, Langård $\mathrm{S}$, Järvholm B, Frentzel-Beyme R, Kauppinen T, Stücker I. Cancer mortality among European asphalt workers: an international epidemiological study. II. Exposure to bitumen fume and other agents. Am J Ind Med. 2003;43(1):28-39.

7. Randem BG, Langård S, Dale I, Kongerud J, Martinsen JI, Andersen A. Cancer incidence among male Norwegian asphalt workers. Am J Ind Med. 2003; 43(1):88-95.

8. Kauppinen T, Heikkilä P, Partanen T, Virtanen SV, Pukkala E, Ylöstalo P, Burstyn I, Ferro G, Boffetta P. Mortality and cancer incidence of workers in Finnish road paving companies. Am J Ind Med. 2003:43(1):49-57.

9. Olsson A, Kromhout H, Agostini M, Hansen J, Funch Lassen C, Johansen C, Kjaerheim K, Langard S, Stucker I, Ahrens W. A case-control study of lung cancer nested in a cohort of European asphalt workers. Environ Health Perspect. 2010;118(10):1418-24.

10. IARC International Agency for Research on Cancer: Occupational exposures to bitumens and their emissions. https:/www.iarc.fr/en/media-centre/ iarcnews/pdf/IARC_Bitumen_Eng.pdf. (2011). Accessed 20 Dec 2016.

11. Huang $Y$, Bird RN, Heidrich $\mathrm{O}$. A review of the use of recycled solid waste materials in asphalt pavements. Resour Conserv Recy. 2007;52(1):58-73.

12. Ibrahim MR, Katman HY, Karim MR, Koting S, Mashaan NS. A review on the effect of crumb rubber addition to the rheology of crumb rubber modified bitumen. Adv Mater Sci Eng. 2013; https://doi.org/10.1155/2013/415246.

13. NIOSH National Institute for Occupational Safety and Health: Crumbrubber modified asphalt paving: occupational exposures and acute health effects. https://www.cdc.gov/niosh/hhe/reports/pdfs/2001-05362864.pdf. (2001). Accessed 20 Dec 2016. 
14. Lee HC, Wei YH. Mitochondrial role in life and death of the cell. J Biomed Sci. 2000;7(1):2-15.

15. Pavanello S, Dioni L, Hoxha M, Fedeli U, Mielzynska-Švach D, Baccarelli AA. Mitochondrial DNA copy number and exposure to polycyclic aromatic hydrocarbons. Cancer Epidemiol Biomark Prev. 2013;22(10):1722-9.

16. Carugno M, Pesatori AC, Dioni L, Hoxha M, Bollati V, Albetti B, Bonzini M, Fustinoni S, Cocco P, Satta G. Increased mitochondrial DNA copy number in occupations associated with low-dose benzene exposure. Environ Health Perspect. 2012;120(2):210-5.

17. Meyer JN, Leung MC, Rooney JP, Sendoel A, Hengartner MO, Kisby GE, Bess AS. Mitochondria as a target of environmental toxicants. Toxicol Sci. 2013; 134(1):1-17.

18. von Zglinicki T. Oxidative stress shortens telomeres. Trends Biochem Sci. 2002;27(7):339-44.

19. Houben JM, Moonen HJ, van Schooten FJ, Hageman GJ. Telomere length assessment: biomarker of chronic oxidative stress? Free Radic Biol Med. 2008;44(3):235-46.

20. Pavanello S, Pesatori A-C, Dioni L, Hoxha M, Bollati V, Siwinska E, Mielzyńska D, Bolognesi C, Bertazzi P-A, Baccarelli A. Shorter telomere length in peripheral blood lymphocytes of workers exposed to polycyclic aromatic hydrocarbons. Carcinogenesis. 2010;31(2):216-21.

21. Li H, Hedmer M, Wojdacz T, Hossain MB, Lindh CH, Tinnerberg H, Albin M, Broberg K. Oxidative stress, telomere shortening, and DNA methylation in relation to low-to-moderate occupational exposure to welding fumes. Environ Mol Mutagen. 2015;56(8):684-93.

22. Li H, Hilmarsen HT, Hossain MB, Björk J, Hansteen IL, Albin M, Furu Skjelbred C, Broberg K. Telomere length and LINEI methylation is associated with chromosomal aberrations in peripheral blood. Genes Chromosomes Cancer. 2013:52(1):1-10

23. Willeit P, Willeit J, Mayr A, Weger S, Oberhollenzer F, Brandstätter A, Kronenberg F, Kiechl S. Telomere length and risk of incident cancer and cancer mortality. JAMA. 2010;304(1):69-75.

24. Wentzensen IM, Mirabello L, Pfeiffer RM, Savage SA. The association of telomere length and cancer: a meta-analysis. Cancer Epidemiol Biomark Prev. 2011;20(6):1238-50.

25. Fitzpatrick AL, Kronmal RA, Gardner JP, Psaty BM, Jenny NS, Tracy RP, Walston J, Kimura M, Aviv A. Leukocyte telomere length and cardiovascular disease in the cardiovascular health study. Am J Epidemiol. 2007;165(1):14-21.

26. Salpea KD, Humphries SE. Telomere length in atherosclerosis and diabetes. Atherosclerosis. 2010;209(1):35-8.

27. Rode L, Bojesen SE, Weischer M, Vestbo J, Nordestgaard BG. Short telomere length, lung function and chronic obstructive pulmonary disease in 46396 individuals. Thorax. 2013;68(5):429-35.

28. McClean MD, Rinehart RD, Ngo L, Eisen EA, Kelsey KT, Wiencke JK, Herrick RF. Urinary 1-hydroxypyrene and polycyclic aromatic hydrocarbon exposure among asphalt paving workers. Ann Occup Hyg. 2004;48(6):565-78.

29. Brandt $H$, De Groot P. Aqueous leaching of polycyclic aromatic hydrocarbons from bitumen and asphalt. Water Res. 2001;35(17):4200-7.

30. IARC International Agency for Research on Cancer: IARC monographs on the evaluation of carcinogenic risks to humans - chemical agents and related occupations (benzo(a)pyrene). https://monographs.iarc.fr/ENG/ Monographs/vol100F/mono100F-14.pdf. (2012). Accessed 20 Dec 2016.

31. Svendsen $\mathrm{KH}$, Svedahl SR, Lindh CH, Palmgren KB. Urinary 8-oxo-7, 8dihydro-2'-deoxyguanosine concentrations after frying of bacon, a pilot study. Toxicol Environ Chem. 2016:1-10. https://doi.org/10.1080/02772248. 2016.1213262

32. Mazzachi BC, Peake MJ, Ehrhardt V. Reference range and method comparison studies for enzymatic and Jaffe creatinine assays in plasma and serum and early morning urine. Clin Lab. 2000;46(1-2):53-5.

33. Ameer SS, Xu Y, Engström K, Li H, Tallving P, Nermell B, Boemo A, Parada $L A$, Peñaloza $L G$, Concha $G$. Exposure to inorganic arsenic is associated with increased mitochondrial DNA copy number and longer telomere length in peripheral blood. Front Cell Dev Biol. 2016;4:87. https://doi.org/10.3389/fcell. 2016.00087.

34. Rooney JP, Ryde IT, Sanders LH, Howlett EH, Colton MD, Germ KE, Mayer GD, Greenamyre JT, Meyer JN. PCR based determination of mitochondrial DNA copy number in multiple species. Methods Mol Biol. 2015;1241:23-38.

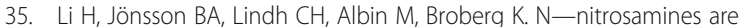
associated with shorter telomere length. Scand J Work Environ Health. 2011; $37: 316-24$.
36. Campo L, Buratti M, Fustinoni S, Cirla PE, Martinotti I, Longhi O, Cavallo D, Foa V. Evaluation of exposure to PAHs in asphalt workers by environmental and biological monitoring. Ann N Y Acad Sci. 2006;1076(1):405-20.

37. Hansen ÅM, Mathiesen L, Pedersen M, Knudsen LE. Urinary 1-hydroxypyrene (1-HP) in environmental and occupational studies - a review. Int J Hyg Environ Health. 2008;211(5):471-503.

38. Väänänen V, Hämeilä M, Kontsas $H$, Peltonen $K$, Heikkilä P. Air concentrations and urinary metabolites of polycyclic aromatic hydrocarbons among paving and remixing workers. J Environ Monit. 2003;5(5):739-46.

39. ACGIH American Conference of Governmental Industrial Hygienists. Threshold limit value for chemical substances and physical agents and biological exposure indices. Cincnnati: ACGIH; 2002. p. 112-4.

40. Watts RR, Wallingford KM, Williams RW, House DE, Lewtas J. Airborne exposures to PAH and PM2. 5 particles for road paving workers applying conventional asphalt and crumb rubber modified asphalt. J Expo Anal Environ Epidemiol. 1998;8(2):213-29.

41. Cavallari JM, Zwack LM, Lange CR, Herrick RF, Mcclean MD. Temperaturedependent emission concentrations of polycyclic aromatic hydrocarbons in paving and built-up roofing asphalts. Ann Occup Hyg. 2012;56(2):148-60.

42. Hou L, Zhang X, Dioni L, Barretta F, Dou C, Zheng Y, Hoxha M, Bertazzi PA, Schwartz J, Wu S, et al. Inhalable particulate matter and mitochondrial DNA copy number in highly exposed individuals in Beijing, China: a repeatedmeasure study. Part Fibre Toxicol. 2013;10:17.

43. Dioni L, Hoxha M, Nordio F, Bonzini M, Tarantini L, Albetti B, Savarese A, Schwartz J, Bertazzi PA, Apostoli P. Effects of short-term exposure to inhalable particulate matter on telomere length, telomerase expression, and telomerase methylation in steel workers. Environ Health Perspect. 2011; 119(5):622-7.

44. Lee HC, Wei YH. Mitochondrial biogenesis and mitochondrial DNA maintenance of mammalian cells under oxidative stress. Int J Biochem Cell Biol. 2005;37(4):822-34.

45. Kim HY, Kim HR, Kang MG, Trang NTD, Baek H-J, Moon JD, Shin JH, Suh SP, Ryang DW, Kook H. Profiling of biomarkers for the exposure of polycyclic aromatic hydrocarbons: lamin-A/C isoform 3, poly [ADP-ribose] polymerase 1 , and mitochondria copy number are identified as universal biomarkers. Biomed Res Int. 2014;2014:605135. https://doi.org/10.1155/2014/605135.

46. Pieters N, Koppen G, Smeets K, Napierska D, Plusquin M, De Prins S, Van De Weghe $H$, Nelen V, Cox B, Cuypers A. Decreased mitochondrial DNA content in association with exposure to polycyclic aromatic hydrocarbons in house dust during wintertime: from a population enquiry to cell culture. PLoS One. 2013;8(5):e63208.

47. Bin P, Leng S, Cheng J, Pan Z, Duan H, Dai Y, Li H, Niu Y, Liu Q, Liu Q. Association between telomere length and occupational polycyclic aromatic hydrocarbons exposure. Zhonghua Yu Fang Yi Xue Za Zhi. 2010;44(6):535-8.

48. Nel AE, Diaz-Sanchez D, Li N. The role of particulate pollutants in pulmonary inflammation and asthma: evidence for the involvement of organic chemicals and oxidative stress. Curr Opin Pulm Med. 2001;7(1):20-6.

49. Zhang $X$, Lin S, Funk WE, Hou L. Republished: environmental and occupational exposure to chemicals and telomere length in human studies. Postgrad Med J. 2013;89(1058):722-8.

\section{Submit your next manuscript to BioMed Central and we will help you at every step:}

- We accept pre-submission inquiries

- Our selector tool helps you to find the most relevant journal

- We provide round the clock customer support

- Convenient online submission

- Thorough peer review

- Inclusion in PubMed and all major indexing services

- Maximum visibility for your research

Submit your manuscript at www.biomedcentral.com/submit 